\title{
Errors of the standard in the horizontal-vertical illusion
}

\author{
G. C. AVERY 1,2 \\ MONASH UNIVERSITY
}

Three experiments were conducted to test the claim that the magnitude of the horizontal-vertical illusion in an $L$ figure varies as a function of which component is used as standard. No difference was found in Experiment 1, in which a staircase procedure was used to establish the PSE. However, by the use of a method of adjustment, the magnitude of illusion was affected by the component used as standard in Experiment 2. The results of Experiment 3, in which a staircase procedure was used with $S$ in upright and recumbent body postures, confirmed those of Experiment 1. It was concluded that earlier differences associated with the standard were a methodological accompaniment of the psychophysical technique used.

The vertical line of an inverted $T$ or $L$ figure is judged to be longer than the horizontal, an effect called the horizontal-vertical (HV) illusion. Gardner and Long $(1960 \mathrm{a}, \mathrm{b})$ showed that the illusion is smaller when the horizontal line is standard and the vertical variable. With the vertical as standard, the effect is greater. Gardner and Long (1962) claim to have supported the hypothesis that errors of the standard (ES) are attributable to the relative time involved in centering attention upon standard and comparison lines, i.e., to centration effects (Piaget, 1950; Würsten, 1947). However, more recent data by Begelman and Steinfeld (1967) have not fully confirmed the earlier findings (Gardner \& Long, 1960b). The ES in the $\mathrm{HV}$ illusion were found to vary in both magnitude and direction as a function of various parameters, including line length (Begelman \& Steinfeld, 1967).

The purpose of the first experiment in which a double staircase procedure (Cornsweet, 1962; Wetherill, 1963; Wetherill \& Levitt, 1965) was used to determine the point of subjective equality (PSE) was to establish whether or not ES occur. A second experimeint was conducted to confirm that ES occur in the HV illusion using the method of adjustment, the psychophysical technique used in the studies reviewed above. A third experiment was designed to verify the findings of Experiment 1 with $S$ in upright and recumbent postures.

\section{EXPERIMENT 1}

In view of the conflicting reports
(Begelman \& Steinfeld, 1967; Gardner \& Long, 1960b), the first experiment was designed to examine the ES in the HV illusion. Judgments of the horizontal and vertical lines of an $\mathrm{L}$ figure were compared.

\section{Apparatus and Method}

Subjects. Ten men and four women student volunteers participated.

Apparatus. A black metal box, in the front of which was cut an $\mathrm{L}$ figure, was placed on a table surrounded by black drapes. Two $0.5 \times 100 \mathrm{~mm}$ slits, uniformly illuminated from inside, were arranged to form an $\mathrm{L}$ with the point of intersection at the lower left. A system of sliding shutters permitted variation in the length of the lines between 50 and $100 \mathrm{~mm}$ about their outer ends. Length could be read to the nearest $1.0 \mathrm{~mm}$, using a circular scale at the rear of the box. The luminance of both lines was $.15 \mathrm{~mL}$. Full details of the stimulus box have been reported elsewhere (Avery \& Day, 1969).

$A$ biteboard stand carrying an adjustable stool maintained the distance between S's eyes and the figure at $100 \mathrm{~cm}$. The visual angle subtended by the $75 \cdot \mathrm{mm}$ standard line was 4 deg $18 \mathrm{~min}$.

Observation conditions. There were two conditions: one in which the vertical was standard (VS) and the other in which the horizontal was standard (HS). The lighted $L$ figure alone was visible in the otherwise dark room.

Procedure. Each S observed under both conditions, with order of presentation counterbalanced. A double-staircase technique was used to determine the PSE of the variable relative to the standard line. Two staircase series, each beginning with the horizontal and vertical lines equal in length, were randomly "interleaved" (Cornsweet, 1962). Following a procedure described by Wetherill (Wetherill, 1963; Wetherill \& Levitt, 1965), "coarse" steps $(4 \mathrm{~mm})$ were used until six reversals of response from variable "longer" to "shorter," or vice versa, were recorded. Then "fine" (2-mm) steps were used until a further six reversals occurred, beginning at

Table 1

Mean Magnitude, (mm), Variance, and Per Cent Positive Illusion for Experiment 1

\begin{tabular}{lcc}
\hline & HS & VS \\
\hline Mean & 2.70 & 1.90 \\
Variance & 15.17 & 10.77 \\
Per Cent Illusion & 3.6 & 2.3 \\
\hline
\end{tabular}

the mean of the first six reversals. Between judgments, $S$ was instructed to close his eyes. Unrestricted binocular inspection of the figure was permitted, but $S$ was instructed to respond as quickly as possible. A rest of $5 \mathrm{~min}$ was given between conditions.

\section{Results}

The PSE was derived from the mean of the six comparison lengths resulting in a reversal in the fine-step sequence. The difference between this mean and $75 \mathrm{~mm}$ served as a measure of the illusion. In the HS condition, a PSE less than $75 \mathrm{~mm}$ indicated a "positive" illusion, and in the VS condition a PSE greater than $75 \mathrm{~mm}$ indicated a "positive" effect. In Table 1, the mean magnitude, variance, and per cent of positive illusion are shown for each condition.

The number of independent hypotheses that could be tested was limited to two (Rodger, 1967). The difference in magnitude of illusion between the two conditjons was not significant, according to a $t$ test for related means $[t(13)=1.723$, $p>.05]$. This suggests that ES do not influence the $\mathrm{HV}$ illusion. The difference between the mean of one preselected condition, VS, and $75 \mathrm{~mm}$ was significant $[t(13)=2.1686, p<.05]$, indicating that a significant HV illusion occurred. Since the difference between the means was not significant, and a significant illusion occurred in one condition, it was concluded that a significant illusion also occurred in the second.

\section{EXPERIMENT 2}

Investigations of the HV illusion in which ES were demonstrated (Begelman \& Steinfeld, 1967; Gardner \& Long, 1960a, b, 1962; Wuirsten, 1947) involved the method of adjustment. However, Piaget, Vinh-Bang, and Matalon (1958) failed to detect significant ES effects using a paired-comparisons technique. In Experiment 1, another variant of the constant-stimulus methods, the double-staircase procedure, was employed. Therefore, a second experiment was conducted to verify that ES occur when an adjustment technique is used to determine the PSE.

\section{Apparatus and Method}

Subjects. There were $14 \mathrm{Ss}$, nine men and five women, all student volunteers. 
Apparatus and observation conditions. The apparatus and observation conditions were identical to those described for Experiment 1.

Procedure. Each S observed under both conditions, with order of presentation counterbalanced. Since it was not practicable for $S$ to manipulate the lengths of the lines himself, a variant of the method of adjustment in which $S$ directs $E$ how to adjust the variable was used (Woodworth \& Schlosberg, 1954). Bracketing was permitted until $\mathbf{S}$ was satisfied that the two lines were equal in length. The five ascending and five descending trials alternated with one another. The standard line was $75 \mathrm{~mm}$ long. On ascending trials, the variable started at $60 \mathrm{~mm}$, and on descending trials at $90 \mathrm{~mm}$. Between judgments, $S$ closed his eyes.

\section{Results}

The PSE was derived from the mean of the 10 trials for each condition. The mean magnitude, variance, and per cent of positive illusion for both conditions are shown in Table 2. A t test for related means was used to examine the difference between the means. The difference was significant $[t(13)=2.6257, p<.05]$, indicating that when using an adjustment technique the magnitude of $\mathrm{HV}$ illusion varies when different lines are used as the standard. Again, the HV illusion in the VS condition was significant $[\mathrm{t}(13)=3.8709$, $p<.05]$. Since the larger effect occurred when the horizontal was standard, these data are contrary to those of Gardner and Long (1960b), but consistent with those of Begelman and Steinfeld (1967).

\section{EXPERIMENT 3}

In an earlier experiment (Avery \& Day, 1969), it was shown that the HV illusion is a function of the retinal meridians with which the lines of an $\mathbf{L}$ figure correspond. When $\mathrm{S}$ was tilted through $90 \mathrm{deg}$ to his right, the vertical line, normally overestimated in length by an upright $S$, was underestimated. In both upright and recumbent postures, the gravitationally vertical line was used as the standard. It could be argued, therefore, that ES may have influenced the findings; when $S$ was upright, the ES would have been expected to reduce the illusion, and correspondingly, to have augmented it in the recumbent

Table 2

Mean Magnitudes, ( $\mathrm{mm}$ ), Variances, and Per Cent of Positive Illusion for Experiment 2

\begin{tabular}{lll}
\hline & HS & VS \\
\hline Mean & 4.10 & 2.40 \\
Variance & 4.18 & 4.39 \\
Per Cent Ilusion & 7.3 & 3.2 \\
\hline
\end{tabular}

condition. In the latter condition, the standard fell vertically relative to the retina.

To show the untenability of this possibility, and to verify the findings of Experiment 1, a comparison was made between judgments of horizontal and vertical lines with $S$ both upright and recumbent.

\section{Apparatus and Method}

Subjects. The Ss were 20 men and 36 women, volunteers from an introductory course in psychology.

Apparatus. The stimulus box described in Experiment 1 was attached to a cabin that served to position $S$ upright and recumbent. The box was mounted on a horizontal axis attached to steel supports fixed on the top of the cabin. The latter was open in front, with adjustable leg, hip, shoulder, and head supports, and a biteboard for controlling head position. With S firmly positioned inside, the whole arrangement could be rotated about a horizontal axis and fixed at any angle, including the vertical and horizontal positions. Full details of the cabin are reported elsewhere (Wade, 1968). During tilt, the lines of the $L$ figure were maintained in the gravitational horizontal and vertical. The fixed distance from S's eyes to the figure was $100 \mathrm{~cm}$, at which distance the $75-\mathrm{mm}$ standard subtended a visual angle of $4 \mathrm{deg} 18 \mathrm{~min}$.

Observation conditions. The four conditions were: $\mathbf{S}$ upright, with vertical line standard (SuVs); S upright, with horizontal line standard (SuHs); S recumbent, with vertical line standard (SrVs); $\mathrm{S}$ recumbent, with horizontal line standard (SrHs). When $S$ was upright the vertical line fell along the normally vertical meridian of the eye, and when he was recumbent the vertical line was projected approximately at right angles to the same meridian (Avery \& Day, 1969). Only the L figure was visible in the otherwise dark room.

Procedure. The Ss were allocated randomly to one of the four independent groups, each observing under one condition. The procedure was similar to that described for Experiment 1, with $S$ in either a recumbent or an upright posture. The PSEs were determined by using the double-staircase procedure.

\section{Results}

In Conditions SuHs and SrVs, when the standard line fell along the horizontal meridian of the eye, a PSE less than $75 \mathrm{~mm}$ indexed a positive illusion. Similarly, a PSE greater than $75 \mathrm{~mm}$ indicated a positive illusion in SuVs and SrHs. In Table 3, the mean, variance, and per cent magnitude of positive illusion are shown for each condition.

In this experiment, three orthogonal planned contrasts could be analyzed by F tests (Rodger, 1967). The difference between SuHs and SrHs was not significant $[F(1,52)=.221, p>.05]$, suggesting that ES did not significantly influence the data of an earlier experiment (Avery \& Day, 1969). Neither the difference between the means of SuHs and SuVs $[F(1,52)=.309$, $p>.05]$ nor that between SrHs and SrVs $[F(1,52)=.0675, p>.05]$ was significant. The latter findings fail to demonstrate the occurrence of ES in judgments of the HV illusion, thereby supporting the results of Experiment 1.

\section{DISCUSSION}

The results of the three experiments reported here, in conjunction with the findings of Begelman and Steinfeld (1967), indicate that the hypothesis that ES are due to centration effects is untenable. In Experiment 2, it was shown that ES occur when the method of adjustment is used. When a double-staircase technique is employed, as in Experiments 1 and 3, illusory measures are unaffected by which line is used as standard. Errors of the standard appear to be due largely to the psychophysical procedures used to measure the effect.

It can be noted, also, that the results of Experiment 3 support the conclusions of an earlier paper (Avery \& Day, 1969) that the critical determinant of the HV illusion is the orientation of an $\mathrm{L}$ figure relative to the retina.

\section{REFERENCES}

AVERY, G. C, \& DAY, R. H. Basis of the horizontal-vertical illusion. Journal of Experimental Psychology, 1969, 81, 376-381.

BEGELMAN, D. A., \& STEINFELD, G. An investigation of several parameters of the horizontal-vertical illusion. Perception \& Psychophysics, 1967, 2, 539-543.

CORNSWEET, T. N. The staircase method in psychophysics. American Joumal of Psychology, 1962, 75, 485-491.

GARDNER, R. W., \& LONG, R. I. Errors of the standard and illusion effects with the inverted T. Perceptual \& Motor Skills, 1960a, $10,47-54$.

GARDNER, R. W., \& LONG, R. I. Errors of the standard and illusion effects with $L$-shaped figure. Perceptual \& Motor Skills, 1960b, 10 , 107-109.

GARDNER, R. W., \& LONG, R. I. Control, defence and centration effect: $A$ study of

Table 3

Mean Magnitudes, ( $\mathrm{mm}$ ), Variances, and Per Cent of Positive Illusion for Experiment 3

\begin{tabular}{lllll}
\hline & SuHs & SuVs & SrHs & SrVs \\
\hline Mean & 1.44 & 1.07 & 2.11 & 3.75 \\
Variance & 8.33 & 7.89 & 4.65 & 11.28 \\
Per Cent Illusion & 1.9 & 1.4 & 2.8 & 4.5 \\
\hline
\end{tabular}


scanning behaviour. British Journal of Psychology, 1962, 53, 129-140.

PIAGET, J. The psychology of inteliigence. London: Routledge \& Kegan Paul, 1950.

PIAGET, J., VINH-BANG, \& MATALON, B. Note on the law of the temporal maximum of some optico-geometric illusions. American Journal of Psychology, 1958, 71, 277-282.

RODGER, R. S. Type I errors and their decision basis. British Journal of Mathematical \& Statistical Psychology, 1967, 20, 51-62.

WADE, N. J. Visual orientation during and after lateral head, body, and trunk tilt. Perception \& Psychophysics, 1968, 3, 215-219.
WETHERILL, G. B. Sequential estimation of quantal response curves. Journal of the Royal Statistical Society, 1963, Ser. B, 25, 1-48.

WETHERILL, G. B., \& LEVITT, H. Sequential estimation of points on a psychometric function. British Journal of Mathematical \& Statistical Psychology, 1965, 18, 1-10.

WOODWORTH, R. S., \& SCHLOSBERG, H. Experimental psychology. London: Methuen, 1954.

WURSTEN, H. L'evolution des comparaisons de longeurs de l'enfant à l'adulte. Archives de Psychologie, Genève, 1947, 32, 1-144.
NOTES

1. This work was undertaken while the author was a recipient of a Commonwealth Postgraduate Award. The author wishes to thank Professor R. H. Day for his guidance throughout this research. 2. Address: Department of Psychology, Monash University, Victoria 3168, Australia.

(Accepted for publication October 15, 1969.) 